\title{
Improving aerosol interaction with clouds and precipitation in a regional chemical weather modeling system
}

\author{
C. Zhou, X. Zhang, S. Gong, Y. Wang, and M. Xue \\ Institute of Atmospheric Composition, Chinese Academy of Meteorological Sciences, China Meteorological \\ Administration (CMA), Beijing 100081, China \\ Correspondence to: C. Zhou (zhouch@cma.gov.cn)
}

Received: 30 April 2015 - Published in Atmos. Chem. Phys. Discuss.: 12 June 2015

Revised: 13 November 2015 - Accepted: 13 November 2015 - Published: 18 January 2016

\begin{abstract}
A comprehensive aerosol-cloud-precipitation interaction (ACI) scheme has been developed under a China Meteorological Administration (CMA) chemical weather modeling system, GRAPES/CUACE (Global/Regional Assimilation and PrEdiction System, CMA Unified Atmospheric Chemistry Environment). Calculated by a sectional aerosol activation scheme based on the information of size and mass from CUACE and the thermal-dynamic and humid states from the weather model GRAPES at each time step, the cloud condensation nuclei $(\mathrm{CCN})$ are interactively fed online into a two-moment cloud scheme (WRF DoubleMoment 6-class scheme - WDM6) and a convective parameterization to drive cloud physics and precipitation formation processes. The modeling system has been applied to study the ACI for January 2013 when several persistent haze-fog events and eight precipitation events occurred.

The results show that aerosols that interact with the WDM6 in GRAPES/CUACE obviously increase the total cloud water, liquid water content, and cloud droplet number concentrations, while decreasing the mean diameters of cloud droplets with varying magnitudes of the changes in each case and region. These interactive microphysical properties of clouds improve the calculation of their collection growth rates in some regions and hence the precipitation rate and distributions in the model, showing 24 to $48 \%$ enhancements of threat score for $6 \mathrm{~h}$ precipitation in almost all regions. The aerosols that interact with the WDM6 also reduce the regional mean bias of temperature by $3{ }^{\circ} \mathrm{C}$ during certain precipitation events, but the monthly means bias is only reduced by about $0.3^{\circ} \mathrm{C}$.
\end{abstract}

\section{Introduction}

Aerosols can act as cloud condensation nuclei $(\mathrm{CCN})$ or ice nuclei (IN) to participate in cloud formations, alter the microphysics and lifetime of clouds, and then impact the precipitation (Twomey, 1977; Ramanathan et al., 2001; Seinfeld and Pandis, 1997; Albrecht, 1989), in so-called aerosolcloud interactions (ACI). Most previous research on ACI focusses on single clouds or climate impacts with very limited data on the mesoscale weather, partially due to the difficulties of establishing real and reasonable connections between emissions and aerosol, CCN, clouds, and then precipitation. Aerosols impacted by emissions, processes of microphysics, and atmospheric thermodynamics are in different size ranges and consist of several components which are often temporally and spatially varied (Jacobson et al., 1994; Zhang et al., 1999; X. Y. Zhang et al., 2012; Gong et al., 2003). Some components, such as organic carbon, have a very complex structure and many of their precursors still cannot be detected (Stockwell et al., 1997; Fuzzi et al., 2006; Jacobson et al., 2000). Meanwhile clouds are also the results of complex interactions among atmospheric thermodynamics of different processes. The scale of aerosol-cloud interactions spans from nanometers to thousands of kilometers, incorporating both complex microphysics and scales of clouds and aerosols, and macrophysics of air mass and atmospheric circulation. All of these make it very difficult to establish a direct connection between emissions and precipitation to quantify the effects of aerosol on clouds and precipitation in both climate and weather models (Khain, 2009; Lohmann and Feichter, 2005; Stevens and Feingold, 2009; Tao et al., 2012).

A weather model with aerosol feedbacks is an important and effective way of exploring the interactions between 
aerosols, clouds, and precipitation (Yin et al., 2002; Levin and Cotton, 2009; Tao et al., 2012; Khain, 2009). Currently, two distinct approaches, the bin method and the bulk method, are often used to explore cloud microphysics in the weather models. For bin models, each type of cloud hydrometer is sectionally resolved to represent its mass or size distributions which might change in the course of the model integration (Khain and Sednew, 1996; Khain et al., 2004). The bin method can explicitly resolve cloud microphysics and provide much more rigorous solutions than the bulk approach, but it is limited to single clouds because of the huge computation. The bulk models have been improved from a single-moment approach to a two-moment approach. The two-moment models can predict not only mass, but also number concentrations; this allows more flexibility of the size distribution and enables the mean diameters to evolve, unlike in the single-moment method (Morrison et al., 2005; Seifert and Beheng, 2001; Lim and Hong, 2010).

However, no matter which cloud approach is used, the relationship between aerosols and cloud droplets needs to be established for ACI. One of the existing relationships is described by the Twomey approach which links the cloud droplet number concentration to aerosol number concentration $\left(N_{0}\right)$ by two simplified parameters, the supersaturation $(S)$ and its power exponent $(\kappa)$, and has been widely used in climate and weather models (Ramanathan et al., 2001; Gultepe and Isaac, 1996; Boucher, 1995; Twomey, 1959; Khairoutdinov and Kogan, 2000). In this approach, the two parameters $N_{0}$ and $\kappa$ should vary from region to region. While $\kappa$ has been set to be constant, $N_{0}$ has been roughly classified into four zones: rural, urban, ocean, and remote continents, with no connection to the emissions and production of the actual aerosol distribution in most cases, and with no physical processes of aerosol activations, i.e., CCN. Even though in some models $\mathrm{CCN}$ can be prognostic as a result of advection, activation, and scavenging, aerosol size distribution and the total aerosol number have to be prescribed (Khain et al., 2004; Fan et al., 2012; Yin et al., 2002). This may introduce additional bias into aerosol-cloud interaction, especially for regions like China with high aerosol concentration consisting of different components.

East China is one of the most polluted areas in the world (X. Y. Zhang et al., 2012). High accumulated aerosols and stagnant weather systems frequently contribute to the formation of regional haze-fog events in this region (Horton et al., 2014; R. H. Zhang et al., 2013; X. Y. Zhang et al., 2013; Che et al., 2014). Heavy aerosol pollution has been related to decreased precipitation and a cooling radiative effect elsewhere (Cheng et al., 2005; Zhao et al., 2006; Ma et al., 2010; Wang et al., 2015). Several studies using the two-moment scheme with the highly parameterized Twomey formula, or the bin model for one cloud, show that microphysics of different regimes of clouds and precipitation can be more realistically simulated by adding the impacts of aerosol in China (Zhang et al., 2007; Guo et al., 2014; Fan et al., 2012; Yang et al., 2011). Since high aerosol concentrations alter radiation, cloud microphysics and then the precipitation, the impacts of aerosols on weather systems cannot be ignored in regional weather models.

In order to take into account the effects of aerosol on clouds and precipitation, a comprehensive scheme containing the emissions, aerosols, clouds, and their interaction mechanisms has been developed in GRAPES/CUACE, which is built on the base of the China Meteorological Administration (CMA) Unified Atmospheric Chemistry Environment/Aerosol (CUACE/Aero) (Zhou et al., 2012), and the CMA weather forecasting model Global/Regional Assimilation and PrEdiction System (GRAPES) (Chen et al., 2008). Integrating a time-dependent $\mathrm{CCN}$ formulation from an aerosol activation scheme directly from CUACE enables the quantitative assessment of the impacts of aerosol pollution on clouds and precipitation.

By developing and using the ACI scheme in GRAPES/CUACE here, the aerosol impacts on clouds and precipitation in east China have been investigated for 1-31 January 2013 when a series of long-lasting haze-fog episodes hit this region and eight precipitation events occurred. This paper is divided into five sections, beginning with Sect. 2 for the description of the modeling system, GRAPES/CUACE. Case description and the designs of numerical experiments are detailed in Sect. 3. Results and discussions will be shown in Sect. 4, followed by conclusions in Sect. 5.

\section{ACI scheme established in GRAPES/CUACE}

\subsection{GRAPES/CUACE system}

The CMA new generation of weather forecasting model GRAPES is a fully compressible non-hydrostatic weather model system which uses a semi-implicit and semiLagrangian discretization scheme (Zhang and Shen, 2008; Xu et al., 2008; Chen et al., 2008). It uses an Arakawa$\mathrm{C}$ staggered grid and the central finite-difference approach of second-order accuracy in horizontal coordination, a nonhydrostatic approximation method together with the staggered approach of Charney-Phillips to improve the accuracy of vertical pressure gradients and a semi-implicit and semiLagrangian scheme for temporal and advection discretion. A height-based terrain-following coordinate, which behaves as a natural height coordinate, is used to compromise the Lagrangian trajectory errors in spherical coordinates at high latitudes. The physical packages include cumulus convective, single-moment cloud microphysics, radiative, land surface, and boundary layer processes.

CUACE is a unified atmospheric chemistry environment with four major functional subsystems: emissions, gas-phase chemistry, aerosol microphysics, and data assimilation. It is designed to facilitate the establishment of a chemical weather 
forecasting system using near real time data in China (Zhou et al., 2012, 2008). Seven aerosol components, i.e., sea salts, sand/dust, elemental carbon, organic carbon, sulfates, nitrates, and ammonium salts are sectioned into 12 bins with detailed microphysics of hygroscopic growth, nucleation, coagulation, condensation, dry depositions and wet scavenging in the aerosol module. The gas chemistry module is based on the second generation of the Regional Acid Deposition Model (RADM II) mechanism with 63 gaseous species through 21 photochemical reactions and 121 gas-phase reactions applicable under a wide variety of environmental conditions especially for smog (Stockwell et al., 1990), and prepares the production rates of sulfate and secondary organic aerosol for the aerosol module. Emission inputs have been provided by the same emission subsystem (EMIS) of CUACE with the official basic emission sources data updated to the year 2010 (Zhou et al., 2012).

CUACE is fully coupled online to the regional version of GRAPES, establishing the comprehensive modeling system, GRAPES/CUACE, and has been used for radiative feedback research (Wang et al., 2010, 2015).

\subsection{Aerosol activation in the HG scheme}

The sectional aerosol activated scheme developed by Hayder Abdul-Razzak and Ghan (HG scheme) provides a convenient platform to connect sectional aerosols into cloud physics (Abdul-Razzak and Ghan, 2002; Hayder and Ghan, 2000; Abdul-Razzak et al., 1998; Ghan et al., 1995, 1993). This scheme is derived from the basic theory of a Köhler curve to calculate how a particle can be activated under a certain supersaturation in an air parcel. The newly activated $\mathrm{CCN}$ would be parameterized in terms of environmental supersaturation and the upper and low limit of the critical supersaturation for each aerosol bin. This method is very useful for the precise determination of the concentration of droplets nucleated at the cloud base. However, droplet nucleation or aerosol activation can also take place above the cloud base as well, which is induced by increasing supersaturation above the cloud base and lateral entrainment of the surrounding air with dry aerosols (Khain et al., 2000). Therefore, it is not enough to calculate the $\mathrm{CCN}$ at the cloud base only in an air parcel, especially for stratus clouds where turbulence is more important than the vertical movement (Bodenschatz et al., 2010). For these reasons, the HG scheme has been online coupled with both the stratus scheme and the convective scheme in GRAPES. Consequently, aerosols from CUACE can be activated into $\mathrm{CCN}$ as the humid condition is satisfied, not just in the cloud base.

\subsection{Aerosol activation in the Double-Moment 6-class scheme}

The WRF Double-Moment 6-class scheme (WDM6) is introduced into GRAPES since it can predict not only the mass but also the number of droplets and drops (Lim and Hong, 2010). It is developed from the WRF Single-Moment 6-class scheme (WSM6) and needs the CCN input for cloud droplets which provides a direct way for aerosol feedbacks into clouds and precipitation. The original activation scheme is expressed as (K2000) (Twomey, 1959; Khairoutdinov and Kogan, 2000)

$n_{\mathrm{a}}=\left(n+N_{c}\right)\left(\frac{S_{w}}{S_{\max }}\right)^{\kappa}$,

where $n$ is the aerosol number concentration, $\kappa$ is the activation power exponent, $S_{\max }$ is the maximum supersaturation to activate all the aerosols, and $S_{w}$ is the air supersaturation. The change rate of cloud droplet number concentration due to $\mathrm{CCN}$ activation is given by

$\frac{\partial N_{c}}{\partial t}=\frac{\max \left\{0,\left(n+N_{c}\right) \min \left[1,\left(\frac{S_{w}}{S_{\max }}\right)^{\kappa}\right]-N_{c}\right\}}{\Delta t}$.

In this activation scheme, $n, \kappa$, and $\max S_{\max }$ are usually preset just as in the Twomey formula, with the inherited shortcomings due to the insufficient information of real aerosols. To overcome these, the aerosol size and composition information from CUACE and the humid and thermal information from GRAPES are used in the HG scheme to calculate the $\mathrm{CCN}$ at each time step, which is then fed into WDM6 to replace the preset CCN by the scheme of K2000.

An aerosol particle can be quickly activated into $\mathrm{CCN}$, usually in less than a second, as the atmosphere reaches the critical supersaturation of the aerosols (Kogan, 1991). In models with relatively coarse resolution like GRAPES, supersaturation cannot be easily satisfied because of the insufficient information of inhomogeneous turbulence and vertical movements even when the grid-mean relative humidity is over about 85 to $90 \%$. Local supersaturation around a particle can be satisfied, through which clouds can be formed. As the local supersaturation is not only decided by the mean fields, a parameterized scheme has been developed to add the effect of local turbulence and vertical movements to the supersaturation in HG scheme for WDM6 in GRAPES. The turbulence effect is assumed to be proportional to the mean relative humidity and inversely proportional to both the horizontal wind speed and the vertical height.

\subsection{Aerosol activation in the KF scheme}

Stratiform and convective precipitation are the two precipitation regimes that cannot be mutually excluded. The former refers to precipitation with low vertical motions, and the latter to stronger precipitation (Houze, 1997). These two regimes can be fully explicit in mesoscale model, only under the condition that the model resolution is below several hundred meters (Molinari and Dudek, 1992), which is very difficult to realize for the online coupled modeling systems such as GRAPES/CUACE. A hybrid approach is often used 
in most mesoscale models, which can explicitly condense water for the stratus precipitation in grid scale, to parameterize convective-scale precipitation in sub-grid scale. In order to fully account for the ACI in the model, the HG scheme has also been coupled to the Kain-Fritch convective parameterization scheme (KF) in GRAPES/CUACE (Kain, 2003; Kain and Fritsch, 1990; Fritsch and Chappell, 1980). The sectional aerosols have been introduced and moved upward or downward as the air mass does in KF. They become activated as soon as the supersaturation satisfies the critical supersaturation by the HG scheme.

Since there is no size information for cloud and rainwater in the bulk convective scheme, a generalized gamma distribution has been introduced to describe the cloud-droplet and raindrop spectra (Cohard and Pinty, 2000; Walko et al., 1995; Clark, 1974).

$$
\begin{aligned}
& N_{X}\left(D_{X}\right)= \\
& \quad N_{X} \frac{\alpha_{X}}{\Gamma\left(v_{X}\right)} \lambda_{X}^{\alpha_{X} v_{X}} D_{X}^{\alpha_{X} v_{X}-1} \exp \left[-\left(\lambda_{X} D_{X}\right)^{\alpha_{X}}\right]
\end{aligned}
$$

Here $\lambda_{X}$ is the slope parameter, and $\alpha_{X}$ and $\nu_{X}$ are two shape parameters. $\lambda_{X}=\left[\frac{\pi}{6} \rho_{w} \frac{\Gamma\left(v_{X}+3 / \alpha_{X}\right)}{\Gamma\left(v_{X}\right)} \frac{N_{X}}{\rho_{a} r_{x}}\right], N_{X}=N_{0}+N_{\mathrm{ccn}}$, $N_{\text {ccn }}$ is the newly activated aerosol number concentration, and $N_{0}$ is the cloud number concentration which is set to be $30 \mathrm{~cm}^{-3}$ in terms of observations in fall in east China (Y. Zhang et al., 2012; Zhang et al., 2011). Normally $\alpha_{X}$ can be specified a priori to be 1 for number concentration size distribution and 3 for mass concentration size distribution. Only $v_{X}$ is left to be tuned through measurements. A parameterization for $v_{X}$ has been proposed through the total droplet number concentration and liquid water content (Geoffroy et al., 2010)

for size spectra of number concentration :

$\alpha_{X}=1, \quad v_{X}=14.5 q_{\mathrm{c}}+6.7$

for size spectra of mass concentration :

$\alpha_{X}=3, \quad v_{X}=1.58 q_{\mathrm{c}}+0.72$.

Here $q_{\mathrm{c}}$ is the liquid water content in the unit of $\mathrm{g} \mathrm{m}^{-3}$. With Eqs. (4) and (5), droplet size distribution in Eq. (3) can be bulk-represented by the total liquid water content and total cloud droplet number concentration which can then include the newly activated aerosols from HG.

The condensed water of the KF scheme is allowed to be removed as precipitation based on an empirical relationship (Ogura and Cho, 1973):

$\delta r_{\mathrm{c}}=r_{\mathrm{co}}\left(1-e^{-c_{1} \delta z / w}\right)$.

Here $c_{1}$ is a constant; $\delta z$ is the height of the layer. The precipitable water $\delta r_{\mathrm{c}}$ in Eq. (4) is inversely proportional to the vertical velocity $w$, which means that a small vertical velocity would produce more $\delta r_{\mathrm{c}}$. As smaller vertical velocity means weaker convection and less $r_{\mathrm{co}}$ (total condense), less precipitable water $\delta r_{\mathrm{c}}$ would be produced. Therefore, $r_{\mathrm{co}}$ and $w$ are offset against each other, which may cause false large convective precipitation. In order to overcome this problem, the size spectrum information of cloud drops and droplets is introduced into the convective clouds, which resolves the total cloud water content and number concentrations, including the newly formed $\mathrm{CCN}$. The new precipitable rainwater, indicated by $r_{\mathrm{p}}$, can be calculated by integrating Eq. (3) to replace $r_{\text {co }}$ in Eq. (6). The threshold for cutoff radius between the droplets and raindrops in the integration is $50 \mu \mathrm{m}$ for deep convective precipitation (Berry and Reinhardt, 1974; Seifert and Beheng, 2001), and $25 \mu \mathrm{m}$ for shallow convective precipitation (Khairoutdinov and Kogan, 2000). Terminal velocity $w_{\mathrm{T}}$ for the raindrops has also been introduced. Finally, Eq. (6) is reformed as

$\delta r_{\mathrm{c}}=r_{\mathrm{p}}\left(1-e^{-w_{\mathrm{T}} / w}\right)$.

Now, the comprehensive interactions of aerosol-cloudprecipitation have been established in GRAPES/CUACE with activated aerosols from CUACE linked into both the stratus and convective clouds to participate in the cloud and precipitation processes.

\section{Case description and numerical experiment designs}

\subsection{Case description}

A series of long-lasting heavy haze-fog events hit the east part of China in January 2013. Climatology analysis shows that the mean number of the hazy days in this period is much higher than the mean value from 1981 to 2010, especially in the three major pollution zones of the North China Plain, Yangtze River Delta, and Zhu River (R. H. Zhang et al., 2013). Meanwhile, the values of the stagnant polluted parameter PLAM (parameter linking air quality to meteorological conditions/haze), a threshold value to distinguish clear and polluted weather, are over 80 in most parts of east China, which indicates strong static weather conditions for pollutant accumulation (X. Y. Zhang et al., 2013; Wang et al., 2012). Surface daily mean $\mathrm{PM}_{2.5}$ concentrations are in the range of $100-150 \mathrm{\mu g} \mathrm{m}^{-3}$ and AOD (aerosol optical depth) is above 1.0 in many surface stations (Che et al., 2014; Wang et al., 2014).

Eight precipitation events also occurred in January 2013, with six of them sweeping over regions south of the Yangtze River as low-pressure systems moving out of the Sichuan Basin each time (Table 1). Two other cases are related to cold fronts and affect the whole east of China. This forms a very good period to study ACI under high-pollution conditions.

\subsection{Numerical experiment designs}

Three sets of experiential runs are designed: $\mathrm{T} 1$ with the single-moment microphysics scheme of WSM6 and original 
Table 1. Threat score comparisons for eight precipitation events for T1, T2, and $\mathrm{T} 3$.

\begin{tabular}{llrrrrr}
\hline Cases & Time period & $\mathrm{T} 3$ & $\mathrm{~T} 2$ & $\mathrm{~T} 1$ & $\begin{array}{r}(\mathrm{T} 3-\mathrm{T} 1) / \\
\mathrm{T} 1 \cdot 100 \%\end{array}$ & $\begin{array}{r}\text { (T2 - T1) / } \\
\mathrm{T} 1 \cdot 100 \%\end{array}$ \\
\hline 1 & & & & 58.9 & 2.5 \\
2 & 12:00 2 Jan-06:00 7 Jan & 0.518 & 0.334 & 0.326 & -5.7 & -15.6 \\
3 & 18:00 7 Jan-12:00 9 Jan & 0.314 & 0.281 & 0.333 & 47.4 & -22.9 \\
4 & 12:00 10 Jan-06:00 13 Jan & 0.482 & 0.252 & 0.327 & 86.2 & -17.4 \\
5 & 00:00 23 Jan-18:00 24 Jan & 0.403 & 0.151 & 0.213 & 89.2 & -29.1 \\
6 & 18:00 25 Jan-12:00 27 Jan & 0.436 & 0.144 & 0.149 & 192.6 & -3.4 \\
7 & 06:00 19 Jan-12:00 22 Jan & 0.532 & 0.349 & 0.389 & 36.8 & -10.3 \\
8 & 06:00 29 Jan-00:00 31 Jan & 0.469 & 0.27 & 0.338 & 38.8 & -20.1 \\
\hline
\end{tabular}

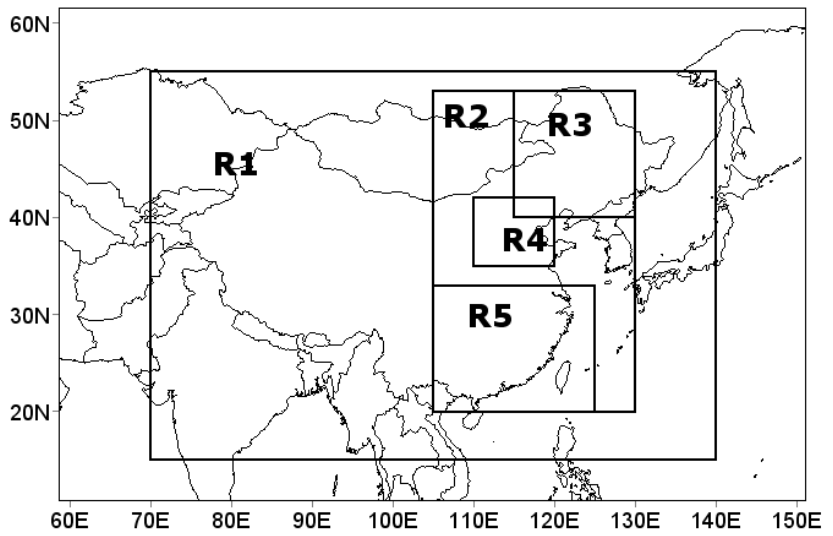

Figure 1. Model domain and five target areas. R1 encompasses the whole of China, R2 east China, R3 northeast China, R4 the North China Plain, and R5 encompasses south China.

KF without aerosol activation; T2 with the WDM6 scheme and the activation scheme K2000; and T3 with the HG activation scheme connected online with WDM6, KF, and CUACE. Five target regions are selected for the evaluation in terms of typical heavy pollution regions over China (Fig. 1). R1 and $\mathrm{R} 2$ cover the whole of China and east China respectively. The areas of R2, R3, R4, and R5 are representative of three typical polluted zones: northeast China, the North China Plain, and south China.

The meteorological initial and boundary conditions, at the resolution of $0.5^{\circ}$, are interpolated from the forecasting outputs of the CMA medium meteorological model T639 in a $6 \mathrm{~h}$ interval. The surface daily and hourly $\mathrm{PM}_{2.5}$ concentrations from CMA Atmosphere Watch NETwork (CAWNET) are used to evaluate the performance of aerosols (Wang et al., 2008; X. Y. Zhang et al., 2012). Precipitation data from the rain gauges in meteorological stations over China are used for the precipitation threat scoring (Wang et al., 2008). Temperature, geopotential height, humidity, and cloud water mixing ratio of NCEP Reanalysis at standard pressure levels from 1000 to $10 \mathrm{hPa}$ are used to evaluate the outputs of GRAPES/CUACE (Kalnay et al., 1996).

\section{Results and discussions}

In order to quantify the impacts of aerosols on precipitation, cloud properties such as the total cloud water content, cloud liquid water content, and mean droplet diameters are analyzed to elucidate the aerosol's effect on clouds. As hourly changes of these variables above are very chaotic, regional means are discussed in order to avoid the interruption of small-scale advection and diffusion. The threat scores (TS) of $6 \mathrm{~h}$ precipitation are also quantitatively analyzed to evaluate the aerosol's effect on precipitation. The changes in temperature and height are also discussed to explore the aerosol effects on the dynamic and thermal state of the atmosphere. Hourly surface aerosol concentrations are compared to the measurements to see the ACI feedbacks on aerosol distribution.

\subsection{Aerosol effects on the clouds}

Regional monthly mean vertical profiles of the total cloud water (the total mass of cloud water, rainwater, ice water, snow, and graupel) and temperature for T1, T2, and T3 together with the NCEP Reanalysis in R1, R2, R3, R4, and R5 are shown in Fig. 2a1-a5 and b1-b5. Compared to T1, $\mathrm{T} 2$, and NCEP Reanalysis in the layers below $600 \mathrm{hPa}$, the total cloud water increases obviously in all five regions for $\mathrm{T} 3$ with a clear peak at about $850 \mathrm{hPa}$. These results indicate that with more realistic aerosols interacting with clouds (T3), more water vapor condenses into cloud water due to the activation of aerosol particles.

The amount of the increasing cloud water for $\mathrm{T} 3$ has very unique regional characteristics. The increase in R1, i.e., nationwide, with plenty of remote dry areas such as Tibet and northwest China, is much less than in R2 which represents the most developed regions in China with a lot of emissions. Of the three typical polluted regions, R3 covers most parts of northeast China with below-freezing temperatures, which is not favorable for warm cloud formation; therefore no obvious increases are found compared to between $\mathrm{T} 2$ and $\mathrm{T} 3$. While the temperature in R4, the most polluted area in China, is near or just above freezing, the condition is favorable for 
Total cloud water

R1

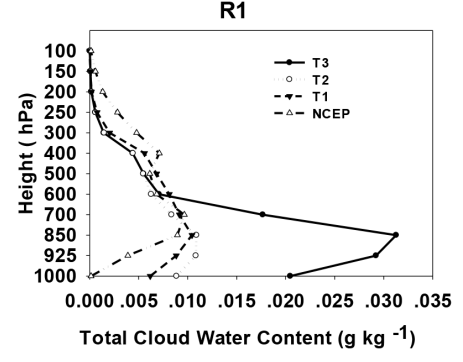

R2

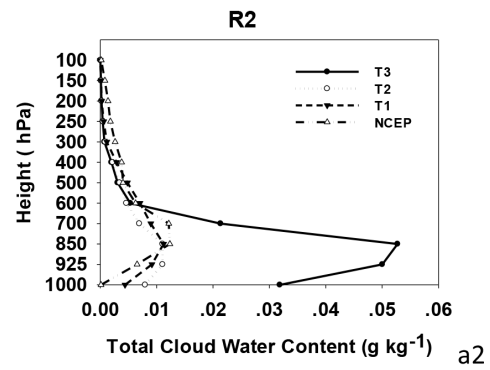

R3

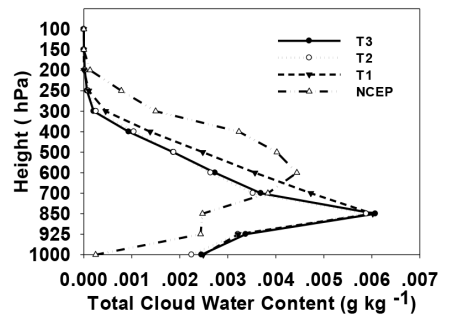

a3
Temperature

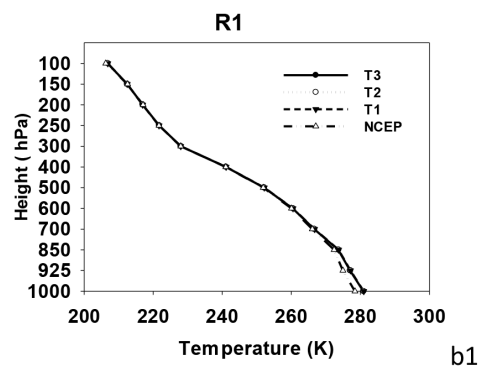

R2

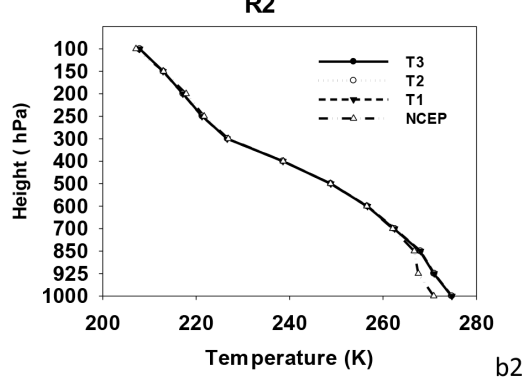

R3

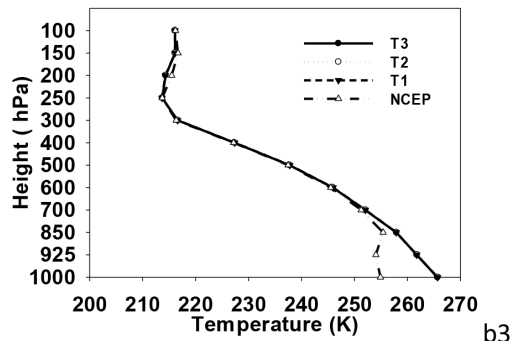

R4

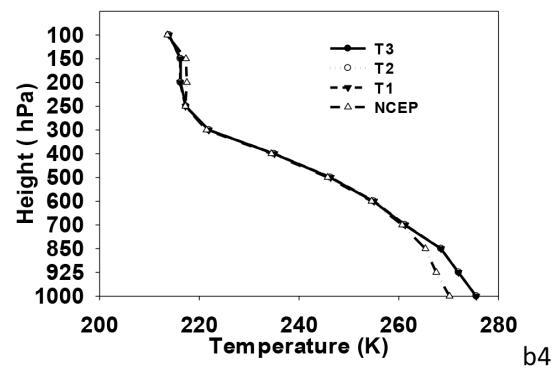

R5

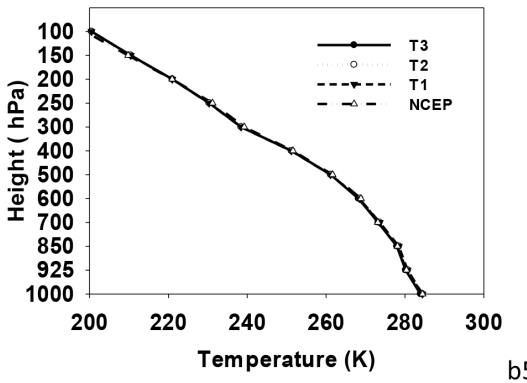

Figure 2. Vertical profiles of regional mean total cloud water content (a1-a5) and temperature (b1-b5) from 1000 to $100 \mathrm{hPa}$ for R1, R2, R3, R4, and R5. T1 denotes WSM6, the control test, T2 is the WDM6 with the K2000 activation scheme, and T3 denotes WDM6 with aerosol activated from CUACE. NCEP is for NCEP Reanalysis. 
the long-lasting haze formation but not a good condition for cloud and precipitation formation with the relatively little cloud water. In R5 where abundant cloud water exists and the temperature under $700 \mathrm{hPa}$ is above freezing, this region has the most enhancement for aerosol activation and the development of warm clouds.

The amount of total cloud water by $\mathrm{T} 1$ and $\mathrm{T} 2$ is compatible with each other because there is no aerosol feeding into the single-moment scheme $\mathrm{T} 1$ and the aerosol activation is based on the prescribed aerosol numbers without spatial variation in T2. Profiles of cloud water from NCEP are close to that of T1 and T2 in all of the five regions. Even though basic variables such as wind, temperature, relative humidity, height, and pressure are most analyzed from measurements, the cloud water data from NCEP Reanalysis are not from direct observations but from cloud physics' diagnosis. Cloud water data from NCEP Reanalysis should be carefully used in the regions affected by high aerosol concentrations.

For all regions, the increases by $\mathrm{T} 3$ in total cloud water contents are driven by liquid water contents (Fig. 3a1-f1). The solid cloud water for $\mathrm{T} 1, \mathrm{~T} 2$, and $\mathrm{T} 3$ is in the same order of $1.0 \times 10^{-3} \mathrm{~g} \mathrm{~kg}^{-1}$ in all the three regions and follows almost the same vertical distribution shapes with tiny difference of height and thickness in each region, showing relatively small effects from aerosols (Fig. 3a2-f2).

The aerosol activation in T3 can also increase the cloud number concentrations which affect the mean diameters of droplets (MDD). The profiles of MDD in R4 and R5 are shown in Fig. 4. MDDs for T3 are all below $10 \mu \mathrm{m}$, about 1 order less than those of $\mathrm{T} 2$, and change little with height in the lower troposphere under $700 \mathrm{hPa}$ (Fig. 4a), showing a clear decrease after aerosols activated into clouds in the North China Plain (R4) and south China (R5). Conventionally, smaller droplets (usually less than $20 \mu \mathrm{m}$ ) need more time to grow into raindrops than the larger drops, which should result in more rains produced in $\mathrm{T} 2$ than in $\mathrm{T} 3$ after a decrease in MDDs. However, due to the self-collection growth process, which depends on both the MDDs and number concentrations of cloud droplets, the simulations in T2 do not see more rain produced (as discussed in Sect. 4.2).

In order to investigate the combined impacts of both MDDs and number concentrations on rain production, the self-collection kernels for the two-moment WDM6 from Long's work (Long, 1974) is used. As shown in Fig. 4e, self-collection rates (SCRs) of R5 for T3 are the largest among all three tests among the three regions of R3, R4, and R5. They are over $100 \mathrm{~m}^{-3} \mathrm{~s}^{-1}$ under $700 \mathrm{hPa}$, about 1 order of magnitude higher than in T2. This indicates that in R5 even though the activated aerosols from CUACE decrease the MDD which may in some way decrease the selfcollection process, the high concentration of cloud droplets from aerosol activation, 4 orders of magnitudes higher than that of T2, enhances the chance of collision and compromises the decreasing collision trend by MDD. Therefore, the SCRs can explain the phenomenon that the precipitation simulation ability increases obviously for T3 in R5 (in Sect. 4.2). While in the North China Plain (R4), SCRs for T3 and T2 are almost the same, they varied around the value of $2 \mathrm{~m}^{-3} \mathrm{~s}^{-1}$, meaning that a lot of aerosols activate as small cloud drops which grow very slowly into larger ones and stay in the atmosphere for a relatively long time, forming long-lasting haze there (Fig. 4d). In northeast China (R3), SCRs for T3 and T2 are so small that the SCRs could be ignored, which is also consistent with the cold cloud formation (Fig. 4c).

In summary, the aerosol effects on cloud formation are very different in the three typical polluted regions: R3, R4, and R5. As shown above, R3 is controlled by cold cloud formation processes; little impact of aerosol activation can be seen in this region. In R4, the relatively humid layer from the surface to $600 \mathrm{hPa}$ indicates a favorable condition for the formation of long-lasting haze as proven by both the mean diameters of droplets and collection rates. In R5, liquid water for T3 is also 1 order higher than that in R4 and 3 orders of magnitude higher than that in R3. Together with the highest collection rate, R5 consists of good conditions for the formation of precipitation, which is consistent with the improvement of the precipitation simulation ability as discussed below.

\subsection{Aerosol effects on precipitation}

\subsubsection{Regional threat scoring evaluation}

Threat scoring is a common and useful way to quantitatively evaluate the model performance of regional precipitation (Mitternaier et al., 2013; Gilleland et al., 2009). The $6 \mathrm{~h}$ accumulated gauge values from 1400 routine weather stations in CMA are used for the evaluation. The threshold value for the contingency table is $0.1 \mathrm{~cm}$ which is in harmony with the $24 \mathrm{~h}$ threat scoring threshold usually used in most operational weather forecasting centers. Threat scoring for $6 \mathrm{~h}$ precipitation is stricter than $24 \mathrm{~h}$ due to the short timescale. The model precipitation results from the three tests, T1, T2, and $\mathrm{T} 3$, are interpolated into the meteorological stations and compared with the observations through the $2 \times 2$ contingency table to calculate the threat scores for the five target regions: R1, R2, R3, R4, and R5.

The time series of $6 \mathrm{~h}$ precipitation threat score for $\mathrm{T} 3 \mathrm{are}$ consistently higher than those for $\mathrm{T} 2$ and $\mathrm{T} 1$ for all five regions (Fig. 5a-d) with a monthly mean improvement of about $33,45,32,24$, and $50 \%$ respectively (Fig. $5 f-1$ ). The improvement for south China (R5) is the highest which is consistent with the results of active aerosol effects on clouds there. Even in China North Plain (R4) where only two precipitation events occur and last for only 4 days, the mean threat score of T3 is still higher than that of T1 and T2 (Fig. 5c, i). The monthly mean threat scores for $\mathrm{T} 2$ are not higher but slightly lower than that for $\mathrm{T} 1$ in R2, R4, and R5, indicating that without the real aerosol information from CUACE, the two-moment scheme cannot improve the model precip- 
R1

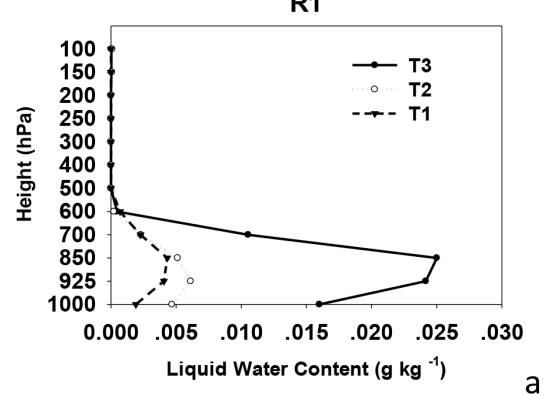

R2

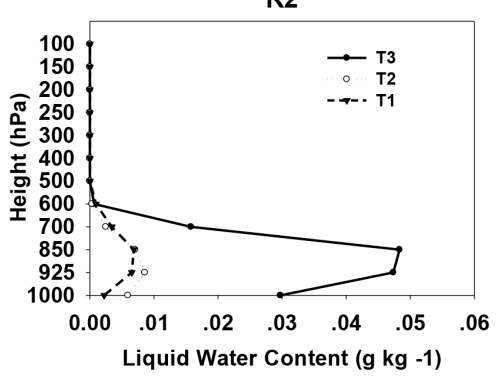

R3

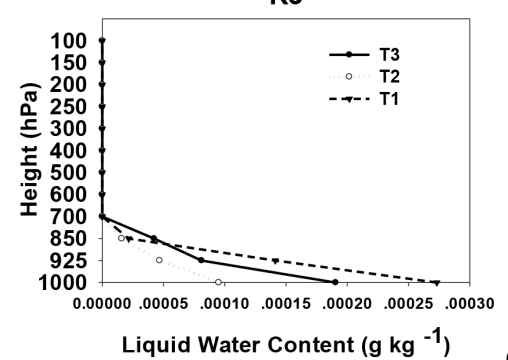

R4

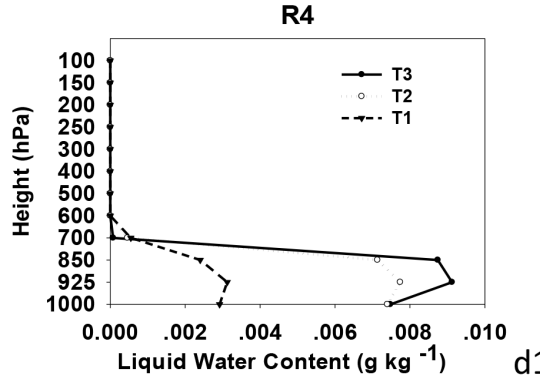

R5

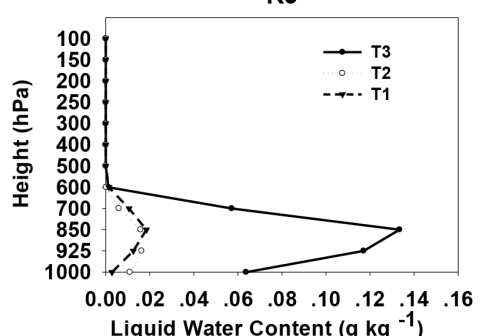

f1

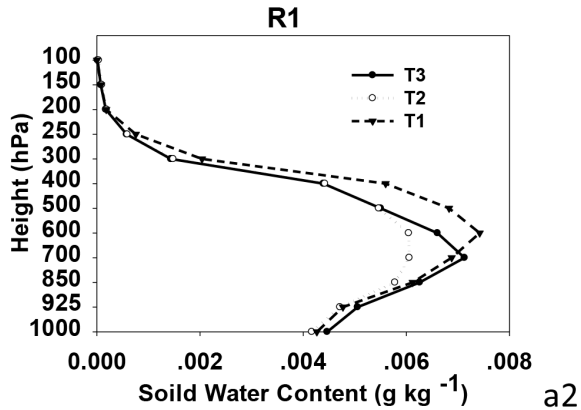

R2

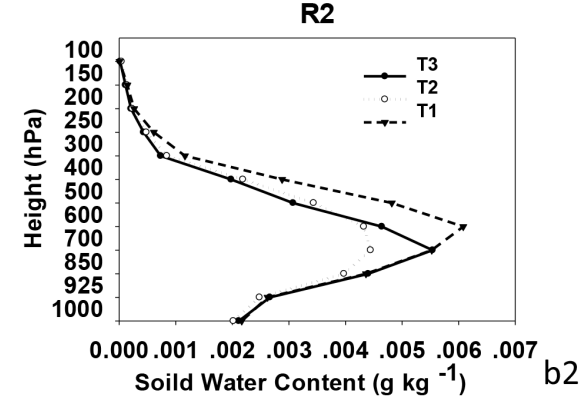

R3

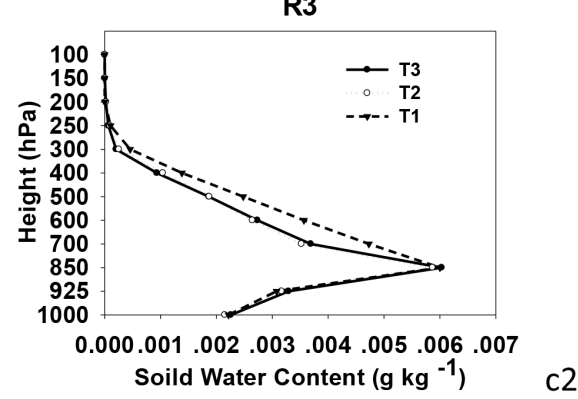

R4

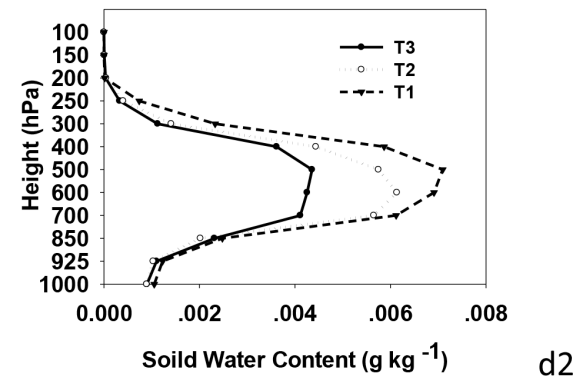

R5

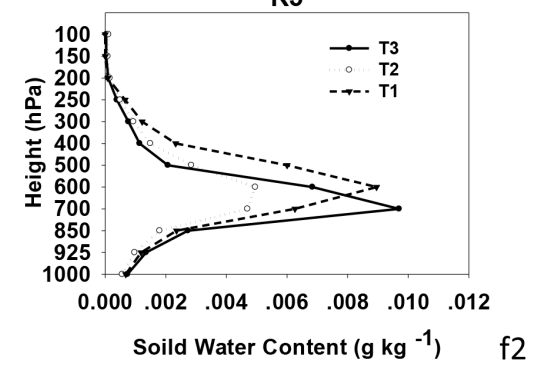

Figure 3. Vertical profiles of regional mean liquid water (a1-f1) and solid water (a2-f2) for R1, R2, R3, R4, and R5 from 1000 to $100 \mathrm{hPa}$. T1 denotes WSM6, the control test, T2 is the WDM6 with the K2000 activation scheme, and T3 denotes WDM6 with aerosol activated from CUACE. NCEP is for NCEP Reanalysis. 


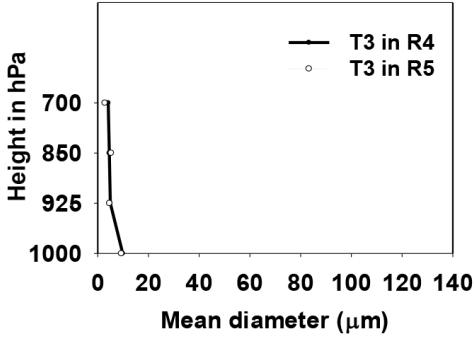

(a)

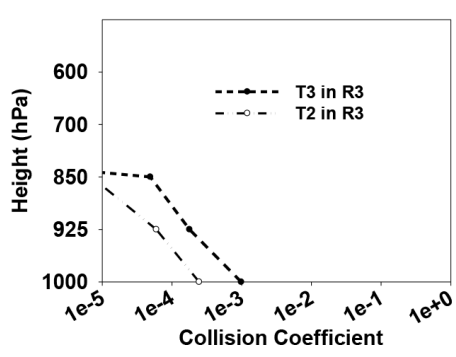

(c)

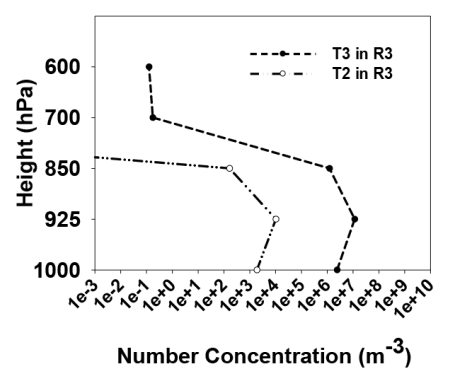

(f)

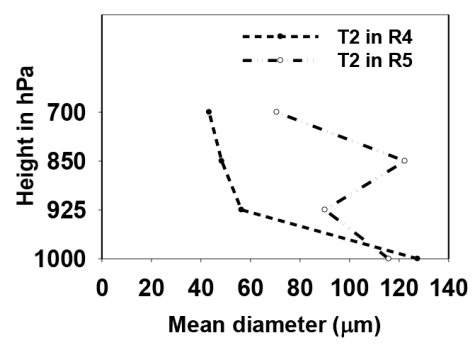

(b)

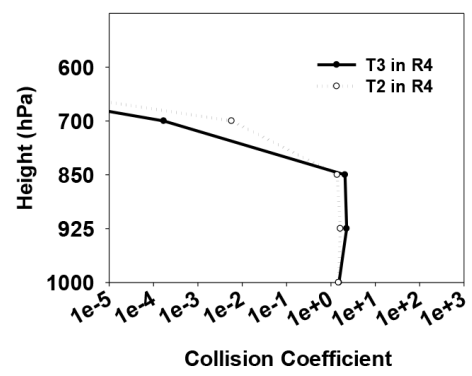

(d)

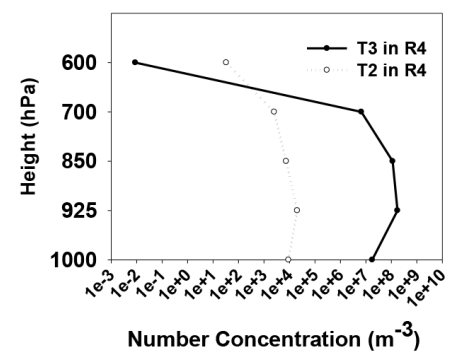

(g)

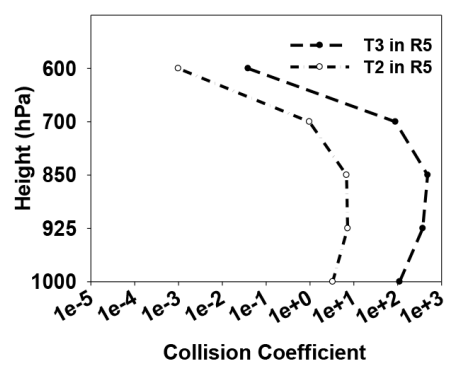

(e)

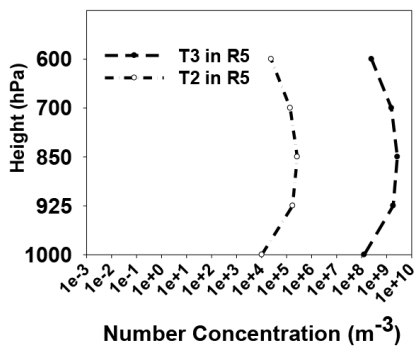

(h)

Figure 4. Panel (a) shows the vertical profile of mean diameters of cloud droplets for T3 in R4 and R5; (b) is the same as (a) but for T2. Panel (c) shows the collision coefficient for T2 and T3 in R3; (d) and (e) are the same as (c) but for R4 and R5. Panel (f) shows the cloud droplet number concentration for T2 and T3 in R3; (g) and (h) are the same as (f) but for R4 and R5.

itation simulation. There is an exception in $\mathrm{R} 3$ where the threat score of $\mathrm{T} 2$ is almost the same as that of $\mathrm{T} 3$. This is because the precipitation is mainly formed by icy clouds in north China (R3) in January and few aerosols can be activated into cloud droplets to participate in cloud processes, resulting in a small threat scoring difference between $\mathrm{T} 2$ and T3. It can also indicate that the WDM6 does improve the microphysics for cold cloud formation as the threat scores in $\mathrm{T} 2$ and $\mathrm{T} 3$ are both higher than that of $\mathrm{T} 1$ in $\mathrm{R} 3$.

To evaluate the overall performance, false alarms or missing events need to be considered. The monthly biases of precipitation simulation, namely (hits + false alarm) / (hits + misses), which infer the over- (larger than 1) or under- (less than 1) estimates of the rain frequency, are $0.73,0.75$, and 1.13 for $\mathrm{T} 1, \mathrm{~T} 2$, and $\mathrm{T} 3$ in $\mathrm{R} 1$ respectively (Table 2). This means that the underestimation in $\mathrm{T} 1$ and $\mathrm{T} 2$
Table 2. Biases for the five regions of R1-R5 and three tests T1-T3.

\begin{tabular}{rrrrrr}
\hline & R1 & R2 & R3 & R4 & R5 \\
\hline T1 & 0.73 & 0.62 & 0.55 & 0.60 & 0.60 \\
T2 & 0.75 & 0.63 & 0.95 & 0.80 & 0.54 \\
T3 & 1.13 & 1.11 & 0.92 & 0.90 & 1.19 \\
\hline
\end{tabular}

has been corrected by adding real aerosol activation in T3. This is also true for cases in R2, R4, and R5. Figure 6 shows a very typical precipitation distribution pattern for T1, T2, and T3 and shows through a visual comparison that the precipitation in T3 is very close to the surface observation in terms of timing and coverage from 08:00 (LST) to 14:00 on 3 January. The threat scores are 0.71 and 0.62 and the biases are 1.35 and 1.19 for $\mathrm{T} 3$, showing a relatively stable and good 

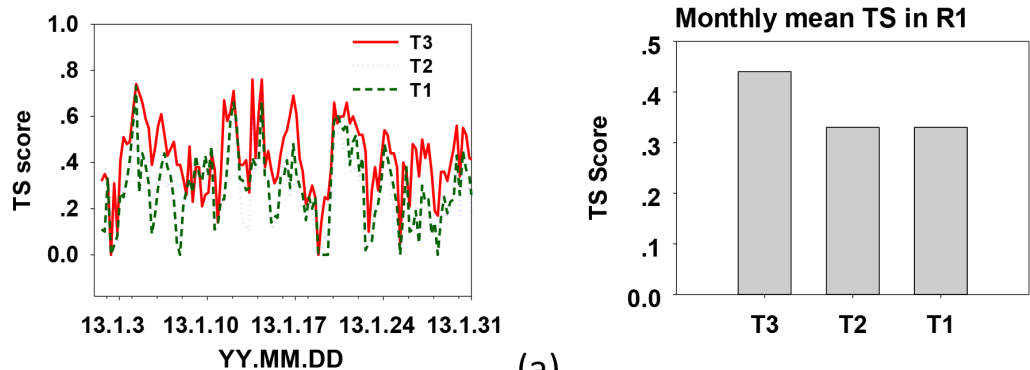

(a)
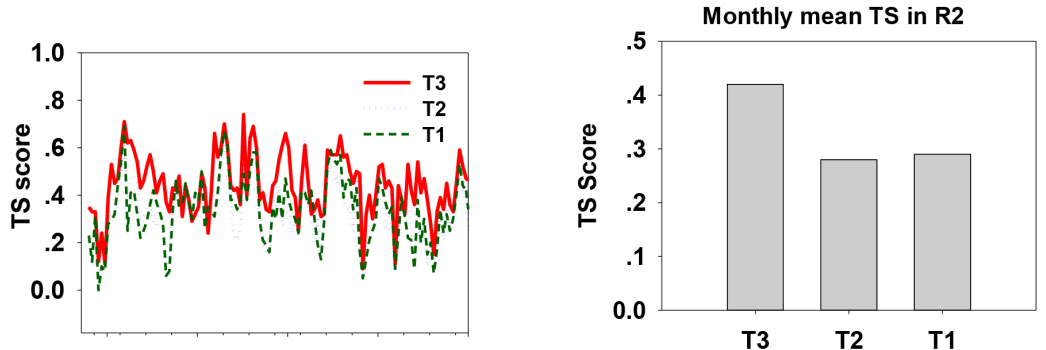

13.1.3 13.1.10 13.1.17 13.1.24 13.1.31 YY.MM.DD

(b)
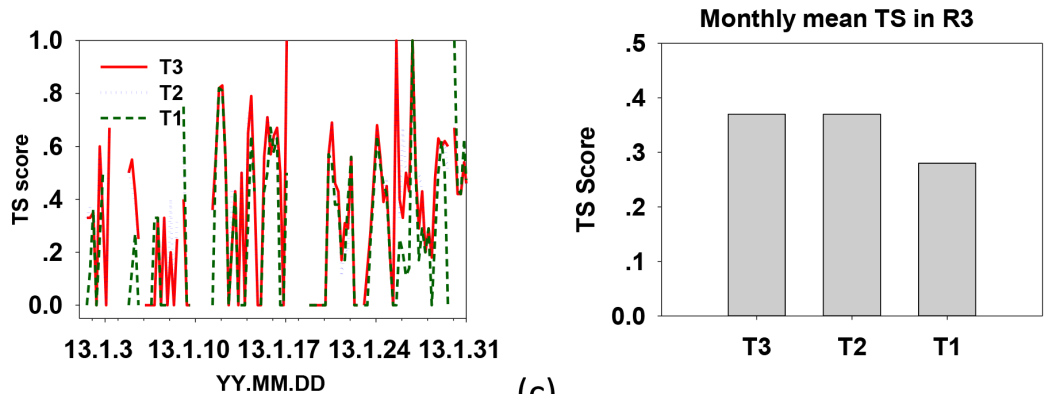

(c)
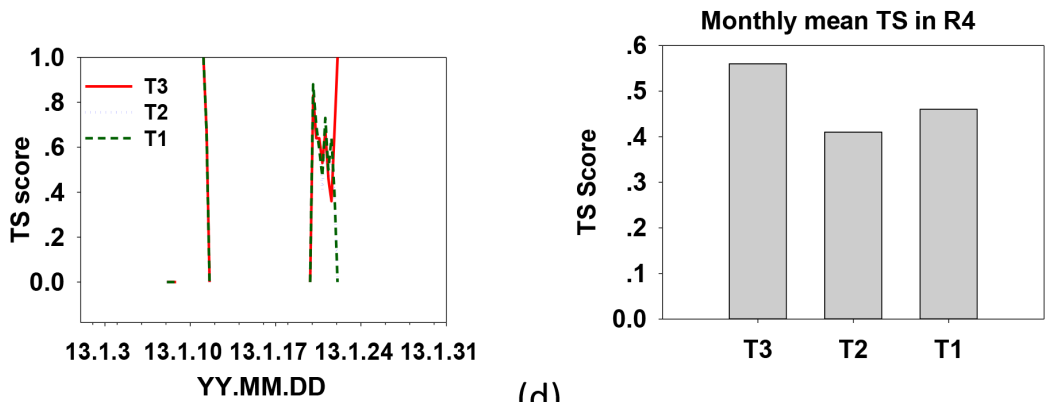

(d)
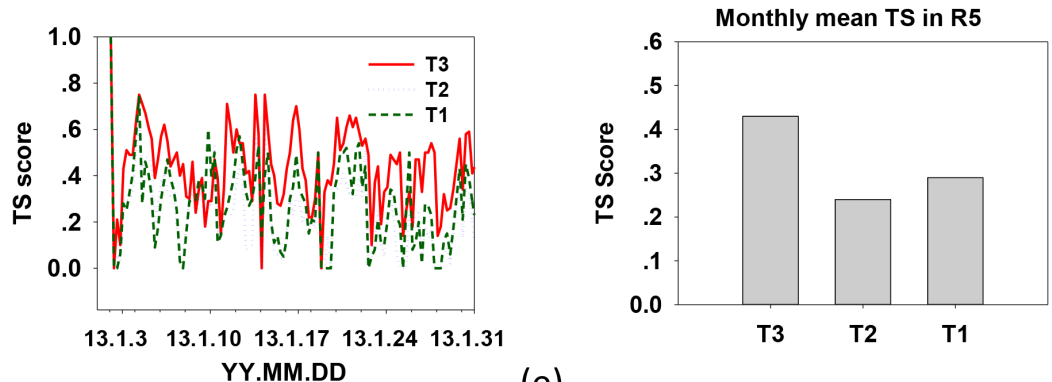

(e)

Figure 5. Time series of $6 \mathrm{~h}$ precipitation threat scores (TS) (a-e) and monthly mean TS (f-h) for R1, R2, R3, R4, and R5. T1 denotes WSM6, the control test, T2 is the WDM6 with the K2000 activation scheme, and T3 denotes WDM6 with aerosol activated from CUACE. 
T1

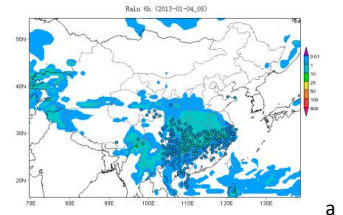

$\mathrm{TS}=0.69$

Bias $=1.14$

T2

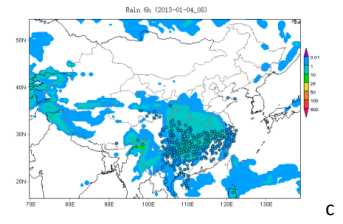

$\mathrm{TS}=0.62$

Bias $=1.04$

T3

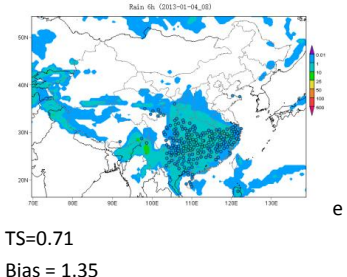

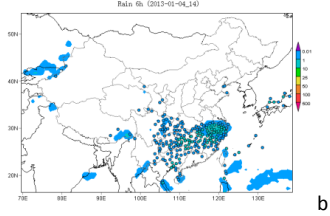

$\mathrm{TS}=0.25$

Bias $=0.32$

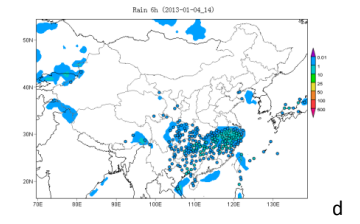

TS $=0.32$

Bias $=0.56$

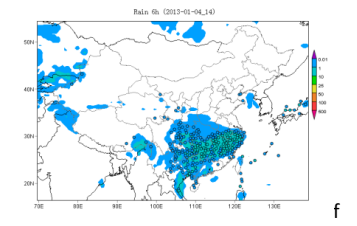

$\mathrm{TS}=0.62$

Bias=1.19

Figure 6. Panel (a) shows the distribution of $6 \mathrm{~h}$ accumulated precipitation (shaded) compared with observations (dotted) with the TS and bias at 08:00 LT 4 January 2013 by T1. Panel (b) is the same as (a) but for 14:00 LT; (c) is the same as (a) but for T2, and (d) is same as (c) but for 14:00 LT. (f) is the same as (a) but for T3, and (f) is the same as (e) but for 14:00 LT.

simulation. As for T1 and T2, threat scores sharply decrease $6 \mathrm{~h}$ after 08:00. The value of biases, much lower than 1, indicates that the decreasing threat score comes from severe underestimation. In northeast China (R3), biases for T2 and T3 are close to 1 and close to each other. This is also consistent with the results of cloud water and the threat score in this region that show that WDM6 performs better for cold clouds and precipitation than the single-moment scheme WSM6.

\subsubsection{Threat scoring for case evaluation}

Two national precipitation events (cases 7 and 8) hit most parts of east China in R2, including R3, R4, and R5; and six cases (case 1 to case 6) hit south China in R5 in January 2013 (Table 1). The mean threat score for all the cases is $0.446,0.246$, and 0.287 for $\mathrm{T} 3, \mathrm{~T} 2$, and $\mathrm{T} 1$ respectively. The mean improvement is about $68.0 \%$, and the most extraordinary improvement is $192.6 \%$ for case 6 . Threat scores for $\mathrm{T} 2$ are generally lower than those for $\mathrm{T} 1$ by $-14.5 \%$. These results are also consistent with the conclusions of the regional precipitation scoring evaluation.

Both the time series' threat score and the case threat score show that the WDM6 scheme alone cannot improve but decrease the ability of precipitation simulation without real aerosol activation information from the cloud microphysics, even though it is more physically based than the one-moment

scheme. Additional errors may have been introduced into the model with the prescribed aerosol number concentrations. Only the WDM6 with the aerosol size and number concentration information from CUACE, driven by emissions and microphysics, as in T3, can significantly improve the model's precipitation simulation ability.

\subsection{Aerosol effects on temperature}

Results of regional mean temperature profiles in the five target areas above $700 \mathrm{hPa}$ are almost the same as from NCEP Reanalysis (Fig. 2b1-b5). The differences between simulations and NCEP Reanalysis are mostly under $700 \mathrm{hPa}$ in all of the five regions and decrease with height. Temperature is from 5 to $10^{\circ} \mathrm{C}$ higher for all the three tests (T1-T3) compared to that of NCEP near the surface in R3 and R4, indicating some problems for GRAPES in the North China Plain. In south China (R5) the regional mean temperature profiles are also almost the same as from NCEP Reanalysis, showing a good performance of GRAPES there. The regional mean difference of temperature for different tests in each region is not very obvious, with the highest value of about $0.2^{\circ} \mathrm{C}$ near the surface located in south China between T3 and T1. Above the surface or in other regions, the mean temperature difference is not significant $\left(<0.05^{\circ} \mathrm{C}\right)$. This means that the regional mean temperature changed by the aerosol is not obvious. This is also the case for the geopotential heights.

The time series of differences in the regional mean temperature biases between $\mathrm{T} 3 \& \mathrm{~T} 1$ and $\mathrm{T} 2 \& \mathrm{~T} 1$ in the three typical polluted areas (R3, R4, and R5) in east China at the three layers are shown in Fig. 7. T3 can clearly decrease the temperature biases below $700 \mathrm{hPa}$ most of the time in all three regions. The difference magnitude decreases from 1000 to $700 \mathrm{hPa}$, showing the clear impact of aerosol below $700 \mathrm{hPa}$ in these layers. The largest decrease is about $3{ }^{\circ} \mathrm{C}$ near the surface and about $1{ }^{\circ} \mathrm{C}$ even at $700 \mathrm{hPa}$ in R5 during the precipitation event from 19 to 22 January. The difference is less than $0.5^{\circ} \mathrm{C}$ in $\mathrm{R} 3$ and $\mathrm{R} 4$ most of the time. It also shows that $\mathrm{T} 2$ increases the biases with the largest increase in R5. T2 might even at some times decrease the biases, but with a lower magnitude compared to that of T3.

The above analysis also shows that WDM6 with the activation scheme $\mathrm{K} 2000$ can introduce errors to the atmospheric temperature fields because of the missing details of aerosol size and component information. The errors would increase with the intensity and frequency of the precipitation. Similarly to the conclusion from the threat scoring analysis, only the two-moment scheme with the real-time aerosol activation can reduce the temperature bias and increase the model's ability to simulate precipitation. 

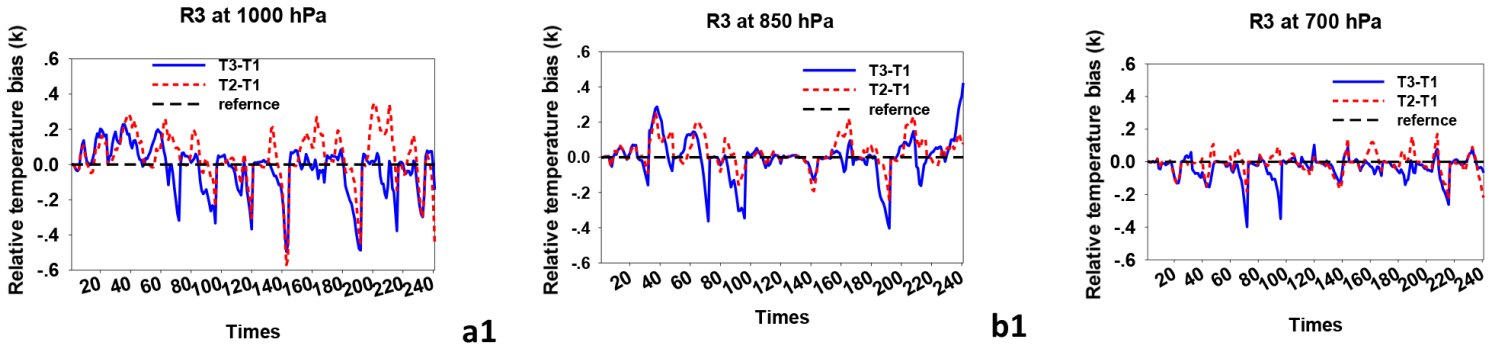

b1

Times

c1
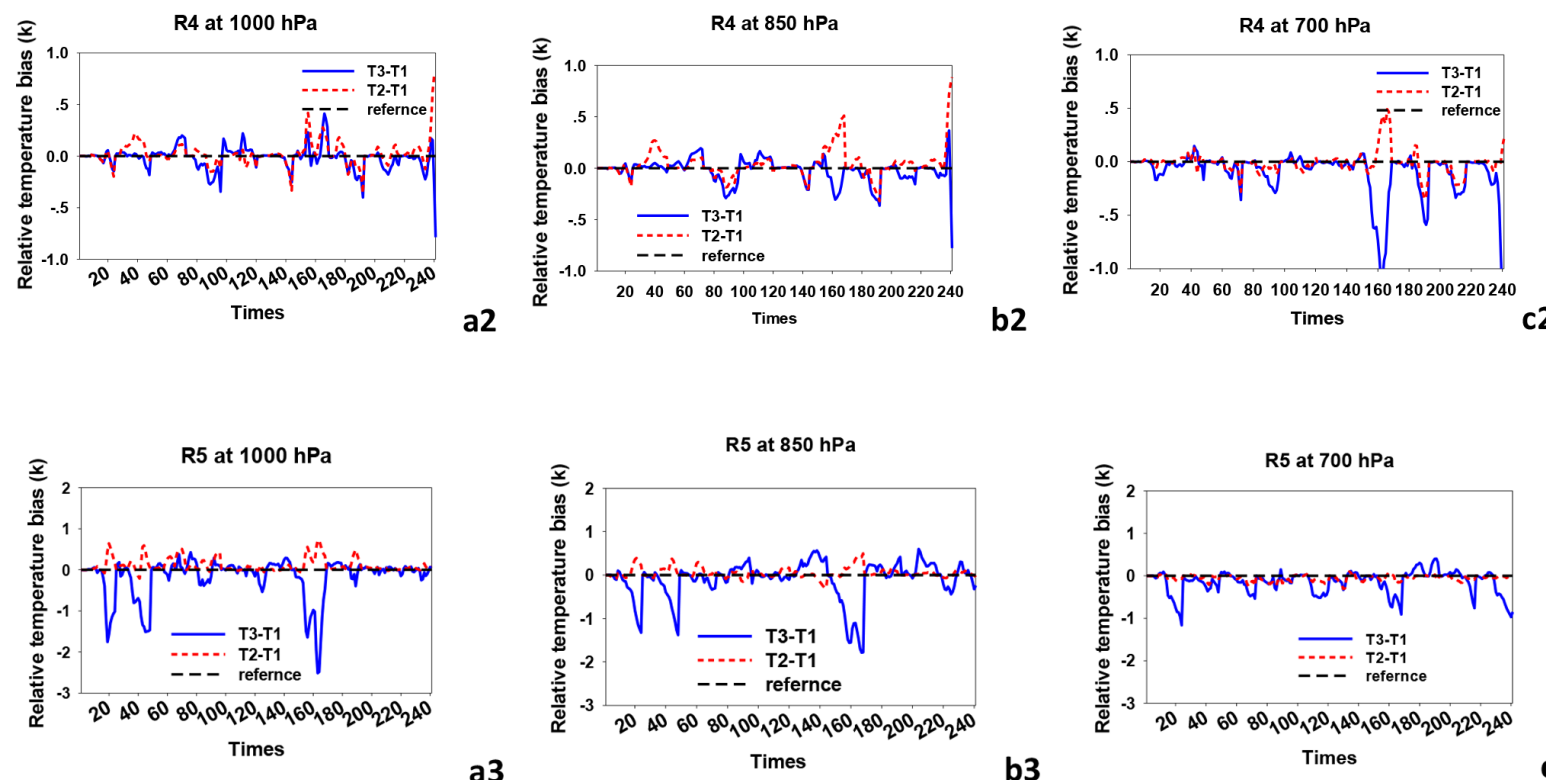

b3

c3

Figure 7. Temperature bias differences between T3 and T1, and T2 and T1 at heights of 1000, 850, and $700 \mathrm{hPa}$ for the regions of R3 (a1-a3), R4 (b1-b3), and R5 (c1-c3).
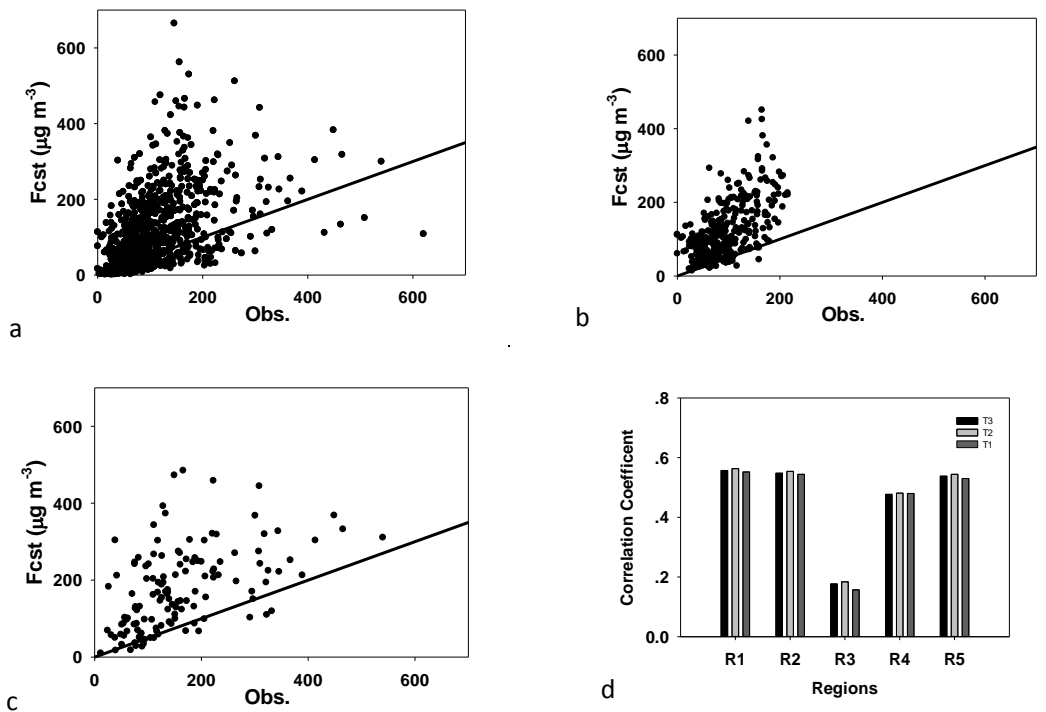

Figure 8. Panels (a), (b), and (c) display scatter plots of daily average $\mathrm{PM}_{2.5}$ between the model and the observations for T3 in R1, R4, and R5. Panel (d) depicts correlation coefficients of $\mathrm{PM}_{2.5}$ between the simulation and measurements for T1, T2, and T3 in the regions of R1, R2, R3, R4, and R5. Fcst denotes forecast. 


\subsection{Feedbacks on surface aerosol simulation}

To realistically simulate the aerosol impacts on clouds, a good performance of $\mathrm{PM}_{2.5}$ simulation, including aerosol sizes and vertical distributions, is critical. Due to limited available observations during the simulation period, only daily averages of $\mathrm{PM}_{2.5}$ concentrations from GRAPES/CUACE have been interpolated and compared with the observations in 32 stations from CAWNET, which have been sorted into the five target regions from R1 to R5. Scatter plots in Fig. 8a-c for $\mathrm{PM}_{2.5}$ simulation for R1, R4, and R5, the nationwide region and the two regions more significantly affected by aerosols, show that the daily average particle mass concentrations between the observations and model outputs are within a factor of 2 . This is compatible with the simulation level of particle matter in most models.

Total correlation coefficients for $\mathrm{T} 1, \mathrm{~T} 2$, and $\mathrm{T} 3$ in $\mathrm{R} 1$ to R5 have been plotted in Fig. 8d. Correlation coefficients for $\mathrm{R} 1, \mathrm{R} 2$ and R5 are above 0.54 for all three tests. Correlation coefficients for R4 are about 0.48 for the three tests. This shows a relative stable and reasonable performance for $\mathrm{PM}_{2.5}$ over these four regions. Correlation coefficients for R3 are only about 0.2 for the three tests, showing a relatively poor simulation there. These results are a little higher than the result by Zhou 2012 for the same region (Zhou et al., 2012). Figure $8 \mathrm{~d}$ also indicates that the differences of correlation coefficients of the three tests in each region are very small. ACI can increase the correlation coefficient by about $2 \%$ in terms of monthly mean.

\section{Conclusions}

A comprehensive aerosol-cloud-precipitation interaction model has been developed under the CMA chemical weather modeling system GRAPES/CUACE. Simulations with this comprehensive system show that activated aerosols from CUACE that interact with WDM6 in GRAPES/CUACE clearly increase the total cloud water, liquid cloud water, and number concentration of droplets; and decrease the mean diameters of the droplets. It is found that the ultimate efficiency of the transformation of aerosol to clouds and precipitation is controlled by multiple parameters, largely by self-collection growth rates in high aerosol-loading regions.

Studies show that interacting aerosols can obviously increase the model's precipitation performance with a threat scoring improvement from 24 to $48 \%$, and correct the obvious underestimation by the control test. It is found the physically based, two-moment cloud physics model WDM6 in GRAPES/CUACE can produce rational precipitation results with only realistic interactive aerosol inputs in warm and mixed clouds, especially in highly polluted regions. WDM6 can also improve the performance of precipitation in cold clouds compared to the control test with the one-moment scheme WSM6.
It is further found out that the aerosol-cloud-precipitation interactions in GRAPES/CUACE also reduce temperature bias as well, especially under $700 \mathrm{hPa}$, which is in harmony with the fact that most aerosols are located below this layer. The aerosol-cloud interaction can decrease the temperature bias by $3{ }^{\circ} \mathrm{C}$ at some times during the precipitation event. The monthly mean impact by aerosol-cloud interaction is only about $0.3^{\circ} \mathrm{C}$. Aerosol-cloud interaction's feedback to the surface aerosol concentration is not significant and can increase the correlation coefficient by about $2 \%$ in terms of monthly mean.

In this paper, an ACI scheme has been explored mainly in wintertime when convection is not strong and a large part of precipitation is from stratified clouds that can be resolved by WDM6. As the comprehensive and complex relations between emissions, clouds, and precipitation explored in this paper provide a platform to study the impacts of aerosol on the mesoscale weather system on a much wider spatialtemporal scale, the ACI should be investigated in the future at different times for different weather patterns.

Acknowledgements. The authors wish to acknowledge the financial support from the National Basic Program (973) of China (2011CB403404), the National Natural Foundation for Young Scientists of China (1340400501), the Science and Technology support program (2014BAC16B03) and the CMA innovation team for fog-haze monitoring and forecast.

Edited by: J. Brandt

\section{References}

Abdul-Razzak, H. and Ghan, S. J.: A parameterization of aerosol activation. 3. Sectional representation, J. Geophys. Res., 107, 148227, 2002.

Abdul-Razzak, H., Ghan, S. J., and Rivera-Carpio, C.: A parameterization of aerosol activation. 1. Single aerosol type, J. Geophys. Res, 103, 6123-6131, 1998.

Albrecht, B. A.: Aerosols, cloud microphysics, and fractional cloudiness, Science, 245, 1227-1230, 1989.

Berry, E. X. and Reinhardt, R. L.: An Analysis of Cloud Drop Growth by Collection: Part 2. Single Initial Distribution, J. Atmos. Sci., 31, 1825-1831, 1974.

Bodenschatz, E., Malinowski, S. P., Shaw, R. A., and Stratmann, F. Can We Understand Clouds Without Turbulence?, Science, 327 970-971, doi:10.1126/science.1185138, 2010.

Boucher, O.: The sulfate -CCN-cloud albedo effect A sensitivity study with two general circulation models, Tellus, 47B, 281-300, 1995.

Che, H., Xia, X., Zhu, J., Li, Z., Dubovik, O., Holben, B., Goloub, P., Chen, H., Estelles, V., Cuevas-Agulló, E., Blarel, L., Wang, H., Zhao, H., Zhang, X., Wang, Y., Sun, J., Tao, R., Zhang, X., and Shi, G.: Column aerosol optical properties and aerosol radiative forcing during a serious haze-fog month over North China Plain in 2013 based on ground-based sunphotometer measure- 
ments, Atmos. Chem. Phys., 14, 2125-2138, doi:10.5194/acp14-2125-2014, 2014.

Chen, D. H., Xue, J. S., Yang, X. S., Zhang, H. L., Shen, X. S., Hu, J. L., Wang, Y., Ji, L. R., and Chen, J. B.: New generation of multiscale NWP system (GRAPES): General scientific design, Chinese Sci. Bull., 53, 3433-3445, 2008.

Cheng, Y., Lohmann, U., and Zhang, J.: Contribution of Changes in Sea Surface Temperature and Aerosol Loading to the Decreasing Precipitation Trend in Southern China, J. Climate, 18, 13811390, 2005.

Clark, T. L.: A study in cloud phase parameterization using the gamma distribution, J. Atmos. Sci., 31, 142-155, 1974.

Cohard, J.-M. and Pinty, J.-P.: A comprehensive two-moment warm microphysical bulk scheme. I: Description and tests, Q. J. Roy. Meteor. Soc., 126, 1815-1842, 2000.

Fan, J., Leung, L. R., Li, Z., Morrison, H., Chen, H., Zhou, Y., and Wang, Q.: Aerosol impacts on clouds and precipitation in eastern China: Results from bin and bulk microphysics, J. Geophys. Res., 117, D00K36, doi:10.1029/2011JD016537, 2012.

Fritsch, J. M. and Chappell, C. F.: Numerical Prediction of Convectively Driven Mesoscale Pressure Systems. Part 1: Convective Parameterization, J. Atmos. Sci., 37, 1722-1733, 1980.

Fuzzi, S., Andreae, M. O., Huebert, B. J., Kulmala, M., Bond, T. C., Boy, M., Doherty, S. J., Guenther, A., Kanakidou, M., Kawamura, K., Kerminen, V.-M., Lohmann, U., Russell, L. M., and Pöschl, U.: Critical assessment of the current state of scientific knowledge, terminology, and research needs concerning the role of organic aerosols in the atmosphere, climate, and global change, Atmos. Chem. Phys., 6, 2017-2038, doi:10.5194/acp-62017-2006, 2006.

Geoffroy, O., Brenguier, J.-L., and Burnet, F.: Parametric representation of the cloud droplet spectra for LES warm bulk microphysical schemes, Atmos. Chem. Phys., 10, 4835-4848, doi:10.5194/acp-10-4835-2010, 2010.

Ghan, S. J., Chuang, C. C., and Penner, J. E.: A parameterization of cloud droplet nulceation. Part I: Single aerosol type, Atmos. Res., 30, 197-221, 1993.

Ghan, S. J., Chuang, C. C., Easter, R. C., and Penner, J. E.: A parameterization of cloud droplet nucleation. Part II: multiple aerosol types, Atmos. Res., 36, 39-45, 1995.

Gilleland, E., Ahijevych, D., Brown, B. G., Casati, B., and Ebert, E.: Intercomparison of Statial Forecast Verification Methods, Weather Forecast., 24, 1416-1430, doi:10.1175/2009WAF2222269.1, 2009.

Gong, S. L., Barrie, L. A., Blanchet, J.-P., Salzen, K. V., Lohmann, U., Lesins, G., Spacek, L., Zhang, L. M., Girard, E., Lin, H., Leaitch, R., Leighton, H., Chylek, P., and Huang, P.: Canadian Aerosol Module: A size-segregated simulation of atmospheric aerosol processes for climate and air quality models 1. Module development, J. Geophys. Res., 108, 4007, doi:10.1029/2001JD002002, 2003.

Gultepe, I. and Isaac, G. A.: The relationship between cloud droplet and aerosol number concentrations for climate models, Int. J. Climatol., 16, 941-946, 1996.

Guo, X., Fu, D., Guo, X., and Zhang, C.: A case study of aerosol impacts on summer convective clouds and precipitation over northern China, Atmos. Res., 142, 142-157, doi:10.1016/j.atmosres.2013.10.006, 2014.
Hayder, A.-R. and Ghan, S. J.: A parameterization of aerosol activation. 2. Multi aerosol types, J. Geophys. Res., 105, 6837-6844, 2000.

Horton, D. E., Skinner, C. B., Singh, D., and Diffenbaugh, N. S.: Occurrence and persistence of future atmospheric stagnation events, Nature Climate Change, 4, 698-703, doi:10.1038/nclimate2272, 2014.

Houze, R. A.: Stratiform Precipitation in Regions of Convection: A Meteorological Paradox?, B. Am. Meoteorol. Soc., 78, 2179 2196, 1997.

Jacobson, M. C., Hansson, H.-C., Noone, K. J., and Charlson, R. J.: Organic Atmospheric Aerosols: Review and State of the Science, Rev. Geophys., 38, 267-294, 2000.

Jacobson, M. Z., Turco, R. P., Jensen, E. J., and Toon, O. B.: Modeling coagulation among particles of different composition and size, Atmos. Environ., 28, 1327-1338, 1994.

Kain, J. S.: The Kain-Fritsch Convective Parameterization: An Update, J. Appl. Meteorol., 43, 170-181, 2003.

Kain, J. S. and Fritsch, J. M.: A One-Dimensional Entertaining/Detraining Plume Model and Its Application in Convective Parameterization, J. Atmos. Sci., 47, 2784-2802, 1990.

Kalnay, E., Kanamitsu, M., Kistler, R., Collins, W., Deaven, D., Gandin, L., Iredell, M., Saha, S., White, G., Woollen, J., Zhu, Y., Chelliah, M., Ebisuzaki, W., Higgins, W., Janowiak, J., Mo, K. C., Ropelewski, C., Wang, J., Leetmaa, A., Reynolds, R., Jenne, R., and Joseph, D.: The NCEP/NCAR 40-Vear Reanalysis Project, B. Am. Meteorol. Soc., 77, 437-471, 1996.

Khain, A. P.: Notes on state-of-art investigations of aerosol effects on precipitation: a critical review, Environ. Res. Lett., 4, 015004, doi:10.1088/1748-9326/4/1/015004, 2009.

Khain, A. P. and Sednew, I.: Simulation of precipitation formation in the Eastern Mediterranean coastal zone using a spectral microphysics cloud ensemble model, Atmos. Res., 43, 77-110, 1996.

Khain, A. P., Ovtchinnikov, M., Pinsky, M., Pokrovsky, A., and Krugliak, H.: Notes on the state-of-art numerical modeling of cloud microphysics, Atmos. Res., 55, 159-224, 2000.

Khain, A. P., Pokrovsky, A., and Pinsky, M.: Simulation of effects of atmospheric aerosols on deep turbulent convective clouds using a spectral microphysics mixed-phase cumulus cloud model. Part 1: model description and possible applications, J. Aerosol Sci., 61, 2963-2981, 2004.

Khairoutdinov, M. and Kogan, Y.: A new cloud physics parameterization in a large-eddy simulation model of marine stratocumulus, Mon. Weather Rev., 128, 229-243, 2000.

Kogan, Y. L.: The simulation of a convective cloud in a 3-D model with explict microphysics. Part 1: Model description and sensitivity experiments, J. Atmos. Sci., 48, 1160-1189, 1991.

Levin, Z. and Cotton, W. R.: Aerosol Pollution Impact on Precipitation, A Scientific Review, Springer, the Netherlands, 2009.

Lim, K.-S. S. and Hong, S.-Y.: Development of an Effective Double-Moment Cloud Microphysics Scheme with Prognostic Cloud Condensation Nuclei (CCN) for Weather and Climate Models, Mon. Weather Rev., 138, 1587-1612, doi:1510.1175/2009MWR2968.1581, 2010.

Lohmann, U. and Feichter, J.: Global indirect aerosol effects: a review, Atmos. Chem. Phys., 5, 715-737, doi:10.5194/acp-5-7152005, 2005.

Long, A. B.: Solutions to the droplet collection equation for polynomail kernels, J. Atmos. Sci., 31, 1041-1057, 1974. 
Ma, J., Chen, Y., Wang, W., Yan, P., Liu, H., Yang, S., Hu, Z., and Lelieveld, J.: Strong air pollution causes widespread haze-cloud over China, J. Geophy. Res., 115, D18204, doi:10.1029/2009JD013065, 2010.

Mitternaier, M., Roberts, N., and Thompson, S. A.: A long-term assessment of precipitation forecast skill using the fractions Skill Score, Meterol. Appl., 20, 176-186, doi:10.1002/met.296, 2013.

Molinari, J. and Dudek, M.: Parameterization of Convective Prediction in Mesoscale Numberical Models: A Critical Review, Mon. Weather Rev., 120, 326-344, 1992.

Morrison, H., Curry, J. A., and Khvorostyanov, V. I.: A New Double-Moment Microphysics Parameterization for Application in Cloud and Climate Models. Part I: Description, J. Atmos. Sci., 62, 1665-1677, 2005.

Ogura, Y. and Cho, H.-R.: Diagnostic Determination of Cumulus Cloud Populations from Observed Large-Scale Variables, J. Atmos. Sci., 30, 1276-1286, 1973.

Ramanathan, V., Crutzen, P. J., Kiehl, J. T., and Rosenfeld, D.: Atmosphere - Aerosols, climate, and the hydrological cycle, Science, 294, 2119-2124, 2001.

Seifert, A. and Beheng, K. D.: A double-moment parameterization for simulating autoconversion, accretion and self-collection, Atmos. Res., 59, 265-281, 2001.

Seinfeld, J. H. and Pandis, S. N.: Atmospheric Chemistry and Physics: from Air pollution to Climate Change, John Wiley \& Sons, Inc., New York, 1997.

Stevens, B. and Feingold, G.: Untangling aerosol effects on clouds and precipitation in a buffered system, Nature, 461, 607-613, doi:10.1038/nature08281, 2009.

Stockwell, W. R., Middleton, P., Change, J. S., and Tang, X.: The second generation Regional Acid Deposition Model Chemical Mechanizm for Regional Ai Quality Modeling, J. Geophy. Res., 95, 16343-16376, 1990

Stockwell, W. R., Kirchner, F., Kuhn, M., and Seefeld, S.: A new mechanism for regional atmospheric chemistry modeling, J. Geophys. Res., 102, 25847-25879, 1997.

Tao, W.-K., Chen, J.-P., Li, Z., Wang, C., and Zhang, C.: Impact of Aerosols on Convective Clouds and Precipitation, Rev. Geophys., 50, RG2001, doi:10.1029/2011RG000369, 2012.

Twomey, S. J.: The nuclei of natural cloud formation, II, The supersaturation in natural clouds and the variation of cloud droplet concentration, Geofisica Pura e Applicata, 43, 243-249, doi:10.1007/BF01993560, 1959.

Twomey, S. J.: The influence of pollution on the shortwave albedo of clouds, J. Atmos. Sci., 34, 1149-1152, doi:10.1175/15200469(1977)034<1149:TIOPOT>2.0.CO;2, 1977.

Walko, R. L., Cotton, W. R., Meyers, M. P., and Harrington, J. Y.: New RAMS cloud microphysics parameterization Part 1: the single-momnet scheme, Atmos. Res., 38, 29-62, 1995.

Wang, H., Zhang, X., Gong, S., Chen, Y., Shi, G., and Li, W.: Radiative feedback of dust aerosols on the East Asian dust storms, J. Geophy. Res., 115, D23214, doi:10.1029/2009JD013430, 2010.

Wang, H., Shi, G. Y., Zhang, X. Y., Gong, S. L., Tan, S. C., Chen, B., Che, H. Z., and Li, T.: Mesoscale modelling study of the interactions between aerosols and PBL meteorology during a haze episode in China Jing-Jin-Ji and its near surrounding region Part 2: Aerosols' radiative feedback effects, Atmos. Chem. Phys., 15, 3277-3287, doi:10.5194/acp-15-3277-2015, 2015.
Wang, J. Z., Gong, S. L., Zhang, X. Y., Yang, Y. Q., Hou, Q., Zhou, C. H., and Wang, Y. Q.: A ParameterizedMethod for AirQuality Diagnosis and Its Applications, Adv. Meteorol., 2012, 1-10, doi:10.1155/2012/238589, 2012.

Wang, Y., Yao, L., Wang, L., Liu, Z., Ji, D., Tang, G., Zhang, J., Sun, Y., Hu, B., and Xin, J.: Mechanism for the formation of the January 2013 heavy haze pollution episode over central and eastern China, Sci. China Earth Sci., 57, 14-25, doi:10.1007/s11430013-4773-4, 2014.

Wang, Y. Q., Zhang, X. Y., Gong, S. L., Zhou, C. H., Hu, X. Q., Liu, H. L., Niu, T., and Yang, Y. Q.: Surface observation of sand and dust storm in East Asia and its application in CUACE/Dust, Atmos. Chem. Phys., 8, 545-553, doi:10.5194/acp-8-545-2008, 2008.

Xu, G. Q., Chen, D. H., Xue, J. S., Sun, J., Shen, X. S., Shen, Y. F., Huang, L. P., Wu, X. J., Zhang, H. L., and Wang, S. Y.: The program structure designing and optimizing tests of GRAPES physics, Chinese Sci. Bull., 53, 3470-3476, 2008.

Yang, S., Ma, J., Hu, Z., Yan, P., Chen, Y., and Wang, W.: Influence of multi-chemical-component aerosols on the microphysics of warm clouds in North China, Sci. China Earth Sci., 54, 451461, doi:10.1007/s11430-010-4075-z, 2011.

Yin, Y., Wurzler, S., Levin, Z., and Reisin, T. G.: Interactions of mineral dust particles and clouds: effects on precipitation and cloud optical properties, J. Geophys. Res., 107, 4724, doi:10.1029/2001JD001544, 2002.

Zhang, D., Guo, X., Gong, D., and Yao, Z.: The observational results of the clouds microphysical structure based on the data obtained by 23 sorties between 1989 and 2008 in Shandong Province, Acta Meteorol. Sin., 69, 195-207, 2011.

Zhang, R., Li, G., Fan, J., Wu, D. L., and Molina, M. J.: Intensification of Pacific storm track linked to Asian pollution, P. Natl. Acad. Sci., 104, 5295-5299, doi:10.1073/pnas.0700618104, 2007.

Zhang, R. H. and Shen, X. S.: On the development of the GRAPESA new generation of the national operational NWP system in China, Chinese Sci. Bull., 53, 3429-3232, 2008.

Zhang, R. H., Li, Q., and Zhang, R. N.: Meteorological conditions for the persistent severe fog and haze event over eastern China in January 2013, Sci. China Earth Sci., 57, 26-35, doi:10.1007/s11430-013-4774-3, 2013.

Zhang, X. Y., Wang, Y. Q., Niu, T., Zhang, X. C., Gong, S. L., Zhang, Y. M., and Sun, J. Y.: Atmospheric aerosol compositions in China: spatial/temporal variability, chemical signature, regional haze distribution and comparisons with global aerosols, Atmos. Chem. Phys., 12, 779-799, doi:10.5194/acp12-779-2012, 2012.

Zhang, X. Y., Sun, J. Y., Wang, Y. Q., Li, W. J., Zhang, Q., Wang, W. G., Quan, J. N., Cao, G. L., Wang, J. Z., Yang, Y. Q., and Zhang, Y. M.: Factors contributing to haze and fog in China (in Chinese), Chinese Sci. Bull. (Chinese Version), 58, 1178-1187, doi:10.1360/972013-150, 2013.

Zhang, Y., Seigneur, C., Senfeld, H. H., Jacbson, M. Z., and Binkowski, F. S.: Simulation of aerosl dynamics: A comparative review of algorithms used in air quality models, Aerosol Sci. Tech., 31, 487-514, 1999.

Zhang, Y., Yin, Y., Shi, L., Duan, Y., and Wu, Z.: Analysis of Cloud Microphysics Structure over Hebei Region during Autumn of 2007, Plateau Meteorology, 31, 530-537, 2012. 
Zhao, C., Tie, X., and Lin, Y.: A possible positive feedback of reduction of precipitation and increase in aerosols over eastern central China, J. Geophys. Res., 33, L11814, doi:10.1029/2006GL025959, 2006.

Zhou, C. H., Gong, S. L., Zhang, X. Y., Wang, Y. Q., Niu, T., Liu, H. L., Zhao, T. L., Yang, Y. Q., and Hou, Q.: Development and evaluation of an operational SDS forecasting system for East Asia: CUACE/Dust, Atmos. Chem. Phys., 8, 787-798, doi:10.5194/acp-8-787-2008, 2008.
Zhou, C.-H., Gong, S., Zhang, X.-Y., Liu, H. L., Xue, M., Cao, G. L., An, X. Q., Che, H. Z., Zhang, Y. M., and Niu, T.: Towards the improvements of simulating the chemical and optical properties of Chinese aerosols using an online coupled model CUACE/Aero, Tellus B, 64, 18965, doi:10.3402/tellusb.v64i0.18965, 2012. 